\title{
Enhancement of Tissue Lesion Depth by Dual Wavelength Irradiation with the Nd-YAG/KTP Laser: Perspectives for Laser Prostatectomy
}

\author{
F. SCHMIDLIN ${ }^{a}$, G. DELACRÉTAZ ${ }^{b}$, M. OSWALD ${ }^{c}$, C. ISELIN ${ }^{a}$, P. JICHLINSKI ${ }^{c}$, B. MERMILLOD ${ }^{d}$, \\ R. LEMOINE ${ }^{e}$, H-J. LEISINGER ${ }^{c}$, P. GRABER ${ }^{a}$ \\ ${ }^{a}$ Clinic of Urology, Department of Surgery, University Hospital of Geneva (HCUG), Geneva, Switzerland \\ 'Institut d'Optique Appliquée, École Polytechnique Fédérale de Lausanne, Lausanne, Switzerland \\ ${ }^{c}$ Clinic of Urology, Department of Surgery, University Hospital of Lausanne (CHUV), Lausanne, Switzerland \\ ${ }^{d}$ Division d'Informatique Médicale, University Hospital of Geneva (HCUG), Geneva, Switzerland \\ e Department of Pathology, University Hospital Geneva (HCUG), Geneva, Switzerland \\ Correspondence to G. Delacrétaz, Institut d'Optique Appliquée, Ecole Polytechnique Fédérale de Lausanne, CH-Ecublens, \\ 1015 Lausanne, Switzerland \\ Received 16 April 1997; accepted pending revision 4 July 1997; accepted in final form 11 September 1997 (London)
}

\begin{abstract}
The Nd-YAG/KTP laser coagulates and vaporizes prostate tissue. The objective of this study was to investigate the combined effects of both wavelengths and to determine the irradiation parameters allowing the largest lesion volume. Chicken breast tissue was irradiated ex vivo. Consecutive 1064 and $532 \mathrm{~nm}$ Nd-YAG/KTP laser irradiations were performed for different combinations $(30 \mathrm{~W} / 10 \mathrm{~W}, 20 \mathrm{~W} / 20 \mathrm{~W}, 10 \mathrm{~W} / 30 \mathrm{~W})$ with variable total fluence $(1200 \mathrm{~J}, 2400 \mathrm{~J}, 3600 \mathrm{~J})$ and compared to isofluent single wavelengths at $40 \mathrm{~W}$ irradiation. The depths, diameters and volumes of the total lesion as well as the vaporization effects of the $532 \mathrm{~nm}$ wavelength on normal and on priorly coagulated tissue were analysed. Maximum total lesion depths $(p<0.001)$ were found under combined Nd-YAG/KTP $(20 \mathrm{~W} / 20 \mathrm{~W})$ irradiation conditions. Ablation efficacy of the $532 \mathrm{~nm}$ wavelength was reduced after prior $1064 \mathrm{~nm}$ irradiation, but crater depths were increased. Dual wavelength irradiation with the Nd-YAG/KTP laser induces a specific denaturation process. This may represent a new approach to increase the depth of coagulation necrosis, and thus the treated volume, thereby improving long-term results.
\end{abstract}

\section{INTRODUCTION}

For the last $30 \mathrm{yr}$, electrosurgical transurethral prostatectomy represented the gold standard for the treatment of symptomatic bladder outlet obstruction. Recently, the therapy of obstructive benign hyperplasia (BPH) has become a field of rapid change, and a variety of minimally invasive methods are currently under investigation as alternative treatments $(1-5)$, in particular laser prostatectomy.

Laser energy enables tissue removal of the prostate through thermal processes either by coagulation or by vaporization. Coagulation results from the irreversible thermal damage by heating the tissue between 60 and $90{ }^{\circ} \mathrm{C}$. Tissue removal then occurs over a period of weeks as the coagulum liquefies and sloughs. Immediate volatilization results from heating the tissue above $100^{\circ} \mathrm{C}$. Intracellular water is turned into steam which ejects tissue and opens a crater cavity surrounded by a coagulation zone.

Coagulation of prostatic tissue is usually achieved using a deep penetrating laser wavelength. The laser beam is delivered under cystoscopic control using a sidefiring laser fibre or through a balloon within the prostatic urethra (6). Alternatively, the laser beam can be delivered interstitially into the substance of the prostate by transurethral or percutaneous application, creating deep tissue coagulation and leaving the prostatic urethra intact (7). Vaporization effects can be produced in noncontact or contact mode. In the non-contact mode, a sidefiring fibre device is used in order to achieve the necessary high temperatures, either by selecting a highly absorbed 
wavelength or by raising the power density of deep penetrating wavelengths. In the contact mode, incision of the urethral prostate can be obtained by using sapphire or fused-silica fibre tips.

So far, non-contact sidefire coagulation is the most widely used technique. Although encouraging clinical results have been reported (8-11), the technique remains controversial because of two problems. First, the slow elimination of coagulated tissue may cause severe obstructive and irritative postoperative symptoms, even occasionally for several weeks. Second, residual prostate tissue still observed several months postoperatively due to insufficient tissue resorption in case of undertreatment may require re-intervention (3).

In order to overcome these difficulties, there is an increasing interest in vaporization techniques, which enable immediate tissue removal, and interstitial coagulation, which treats the tissue at a depth a transurethral application cannot reach $(1,7)$. The Nd-YAG/ KTP laser takes part in this evolution, since it offers a concept that combines coagulation and vaporization (8). Deep prostatic tissue coagulation is first induced with the penetrating $1064 \mathrm{~nm}$ Nd-YAG laser radiation. The urethral prostate is then incised with the better absorbed $532 \mathrm{~nm}$ KTP radiation in non-contact mode, thus reducing postoperative morbidity and allowing early catheter removal. So far, clinical experiences with this technique are encouraging $(2,8)$.

However, the long-term volume reduction of the prostate, and thus the long-term success rate of the procedure, depends strongly on the coagulation volume achieved, which is related to the coagulation depth. The objective of this study was therefore to investigate systematically the interaction between the two wavelengths, on a simple and well-known biological tissue, and to determine whether their combination may lead to an increased lesion depth.

\section{MATERIALS AND METHODS}

Laser effects were studied ex vivo on chicken breast samples immersed in saline at constant tissue temperature $\left(36^{\circ} \mathrm{C}\right)$. Tissue was irradiated using a direct-firing fibre (Endostat Laserscope, USA) with a core diameter of $600 \mu \mathrm{m}$ positioned perpendicularly to the sample surface. During laser irradiation, the fibre tip was maintained at a constant distance of $2 \mathrm{~mm}$ from the specimen surface, giving a spot diameter of $1.1 \mathrm{~mm}$ on the sample.

A dual wavelength $\mathrm{Nd}-\mathrm{YAG} / \mathrm{KTP}$ laser (Laserscope, USA) providing the Nd-YAG laser fundamental at $1064 \mathrm{~nm}$ and the frequency doubled $532 \mathrm{~nm}$ wavelengths was used. The maximum laser output of the system was $100 \mathrm{~W}$ at $1064 \mathrm{~nm}$ and $40 \mathrm{~W}$ at $532 \mathrm{~nm}$. Irradiations were performed sequentially $(1064 \mathrm{~nm}$ first, then $532 \mathrm{~nm}$ ) for different combinations $(30 \mathrm{~W} / 10 \mathrm{~W}, 20 \mathrm{~W} / 20 \mathrm{~W}, 10 \mathrm{~W} / 30 \mathrm{~W})$ with variable total fluence $(1200 \mathrm{~J}, 2400 \mathrm{~J}, 3600 \mathrm{~J})$, and compared to isofluent single wavelength $40 \mathrm{~W}$ irradiation. The irradiation times for each wavelength were 30,60 and $90 \mathrm{~s}$, corresponding to dual wavelength irradiation times of 60,120 and $180 \mathrm{~s}$. The irradiation time of single wavelength experiments $(40 \mathrm{~W} / 0 \mathrm{~W}, 0 \mathrm{~W} / 40 \mathrm{~W})$ was half that of dual wavelengths irradiation. Each wavelength setting was analysed on six samples for a total of 90 irradiation sites. Due to possible fibre damage during laser irradiation, fibre tip condition and laser output were checked before each laser irradiation.

The specific influences of the laser irradiance and of the irradiation time on the lesion characteristics have been determined in single wavelength experiments (five samples for a total of 40 irradiation sites). Effects of irradiance were studied at laser power output of 20 and $40 \mathrm{~W}$. Effects of irradiation time were studied by comparing $40 \mathrm{~W}$ and $30 \mathrm{~s}$ irradiation with $20 \mathrm{~W}$ and $60 \mathrm{~s}$ irradiation.

Finally, the effect of the tissue denaturation induced by the previous $1064 \mathrm{~nm}$ on the lasertissue interaction process of the $532 \mathrm{~nm}$ output was addressed by comparing lesions induced at $532 \mathrm{~nm}$ on normal (untreated) tissue and tissue previously irradiated by the $1064 \mathrm{~nm}$ output $(120 \mathrm{~s}$ at $20 \mathrm{~W}$ for a total energy of $2400 \mathrm{~J})$. A total of 20 irradiation sites on five samples were analysed.

Under ex vivo conditions, the coagulated tissue was easily recognized macroscopically by its blanching. Minimal blackening and carbonization of the lesion edge was observed after irradiation with the KTP laser. Microscopic evaluation has been validated by histologic verification. Lesions were analysed macroscopically and their three-dimensional extension was measured. Total lesion was defined as tissue damaged by coagulation and vaporization. The total depth, diameter and lesion volumes are reported. The volume 
of the lesion was computed after approximating the actual lesion shape either by a halfellipsoid or by a cylinder. The ablation crater was characterized by its diameter, depth and volume.

The statistical analysis was performed using the BMDP Statistical Software package $(2 \mathrm{~V})$ for multi-way analysis of variance. Multi-way analysis of variance was performed with main factors being wavelength combinations, fluences and chicken breast samples. Interaction between wavelength combinations and fluences were also taken into account. If this interaction was not significant, or only marginally significant, main factors were analysed using all data. In the case of significant difference between wavelength combinations, four orthogonal contrasts were calculated $[0 / 40 \mathrm{vs}$ $10 / 30,30 / 10$ vs $40 / 0(0 / 40+10 / 30)$ vs $(30 / 10+40 /$ $0), 20 / 20$ vs all others]. If there were significant differences between fluence groups, two orthogonal contrasts were evaluated [linear: $30 \mathrm{~s}$ vs $90 \mathrm{~s}$, quadratic: $(30 \mathrm{~s}+90 \mathrm{~s})$ vs $60 \mathrm{~s}$ ].

\section{RESULTS}

\section{Total lesion depth}

The total lesion depths (coagulation and vaporization) measured for the different laser fluence groups investigated are shown in Fig. 1. Total lesion depth showed a significant difference when analysed with regard to wavelength combinations $(p<0.0001)$ and fluence $(p<0.0001)$. A significant $(p<0.0001)$ enhancement of the total tissue lesion depth was observed after combined irradiation with both wavelengths at equal power $(20 \mathrm{~W})$. However, no significant difference was found between the other four irradiation combinations. Total lesion depth is also significantly increased by an increase in irradiation time $(p<0.0001$, lin. ear). The depth of the ablation crater reaches $80 \%$ of the total lesion depth at maximum. Interestingly, the depth of the ablation crater is also maximum at the optimal $20 \mathrm{~W} / 20 \mathrm{~W}$ irradiation conditions (3600 J fluence group).

\section{Total lesion diameter and volume}

The total lesion diameters (coagulation and vaporization) are shown in Fig. 2. At the $20 \mathrm{~W} /$ $20 \mathrm{~W}$ irradiation combination, a statistically significant decrease in the total lesion diam-

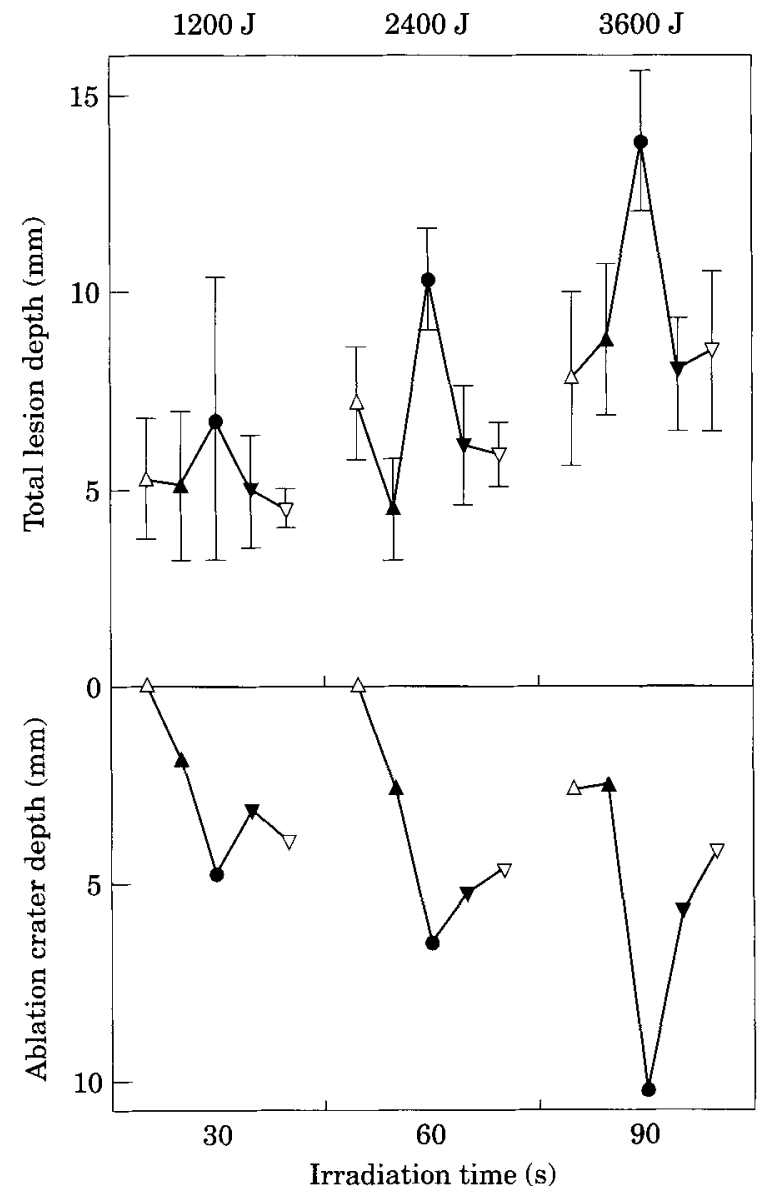

Fig. 1. Total lesion depths induced in chicken breast as a function of wavelength combination and irradiation time. Maximum lesion depth $(p<0.0001)$ is found with the $20 / 20 \mathrm{~W}$ Nd-YAG $(1064 \mathrm{~nm}) / \mathrm{KTP}(532 \mathrm{~nm})$ combination. Note that the synergy effect observed at $20 / 20 \mathrm{~W}$ increases with irradiation time, contrary to other power combinations. $\triangle$, Nd-YAG 40 W/KTP OW; $\triangle$. Nd-YAG 30 W/KTP $10 \mathrm{~W}$; $\bullet$, Nd-YAG $20 \mathrm{~W} / \mathrm{KTP} 20 \mathrm{~W} ; \mathbf{\nabla}$, Nd-YAG $10 \mathrm{~W} / \mathrm{KTP} 30 \mathrm{~W} ; \nabla$, Nd-YAG O W/KTP $40 \mathrm{~W}$.

eter $(p<0.0001)$ was observed. No significant difference was found between the other wavelength combinations. Total lesion diameters were also increased by longer irradiation times $(p<0.0001$, linear $)$.

The total lesion volumes (coagulation and vaporization) are shown in Fig. 3. In contrast to the lesion diameter and depth, no statistically significant difference is observed between all wavelength combinations $(p=0.33)$. At identical fluence, all wavelength combinations yield comparable lesion volumes. Only an increase of the irradiation time leads to significantly larger lesion volume $(p<0.0001$, linear). On the other hand, the volume of the crater induced by tissue vaporization for the highest fluence $(3600 \mathrm{~J})$ represents at maximum only $13 \%$ of the total tissue lesion. 


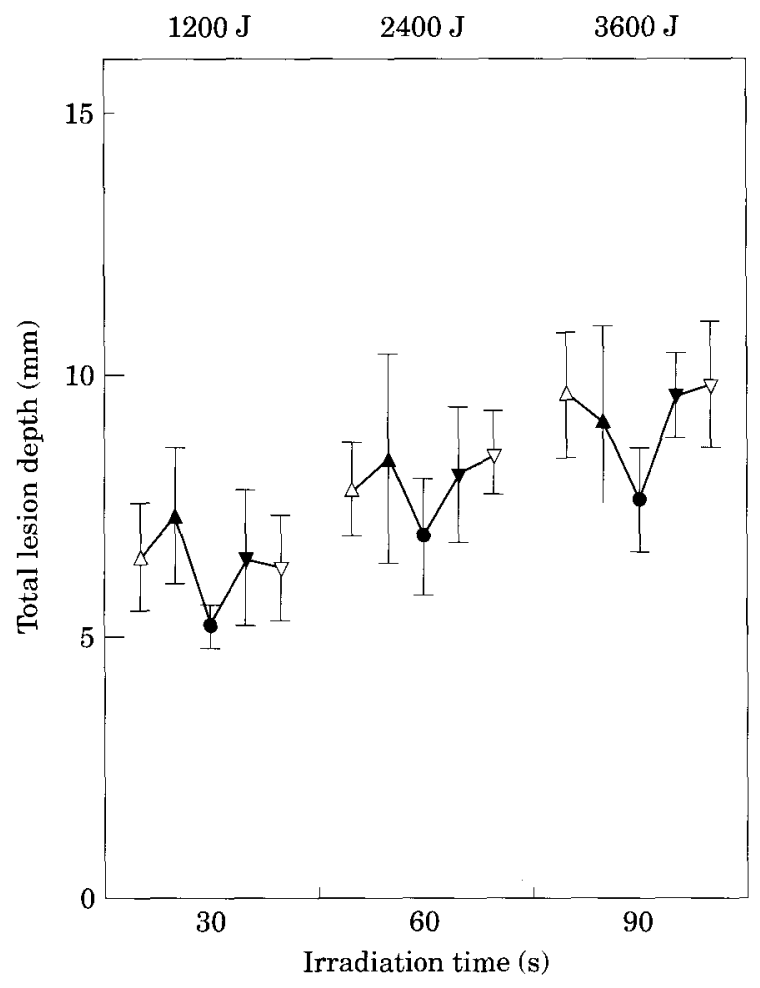

Fig. 2. Total lesion diameters induced in chicken breast as a function of wavelength combinations and irradiation time. Statistically significant decrease $(p<0.0001)$ of the lesion diameter at the $20 \mathrm{~W} / 20 \mathrm{~W}$ irradiation combination. $\triangle$, Nd-YAG $40 \mathrm{~W} / \mathrm{KTP} 0 \mathrm{~W} ; \boldsymbol{\Delta}$, Nd-YAG $30 \mathrm{~W} / \mathrm{KTP} 10 \mathrm{~W}$; - Nd-YAG $20 \mathrm{~W} / \mathrm{KTP} 20 \mathrm{~W} ; \boldsymbol{\nabla}$, Nd-YAG $10 \mathrm{~W} / \mathrm{KTP} 30 \mathrm{~W}$; $\nabla$, Nd-YAG 0 W/KTP $40 \mathrm{~W}$.

\section{Effect of the laser irradiance}

The effect of the laser irradiance on the total lesion depth has been investigated separately for both wavelengths. The total lesion depths generated at two laser powers (20 and $40 \mathrm{~W}$ ) and for two laser doses (1200 and $3600 \mathrm{~J})$ are shown in Fig. 4. No significant effect of irradiance $(p=0.87)$ on the total lesion depth was observed. Only an increase of the irradiation time lead to an increase of the total lesion depth $(p<0.0001)$. Similar observations were made for the total lesion diameters and the total lesion volumes (data not shown).

\section{Effect of previous Nd-YAG coagulation on the KTP ablation efficacy}

Prior irradiation with the Nd-YAG modifies the interaction parameters of the KTP output. First, the immediate tissue volume removal is significantly reduced at $20 \mathrm{~W}$ and $30 \mathrm{~W}$ KTP $(p<0.0001)$ [Fig. 5(a)]. Second, the total diameter of the crater is significantly reduced

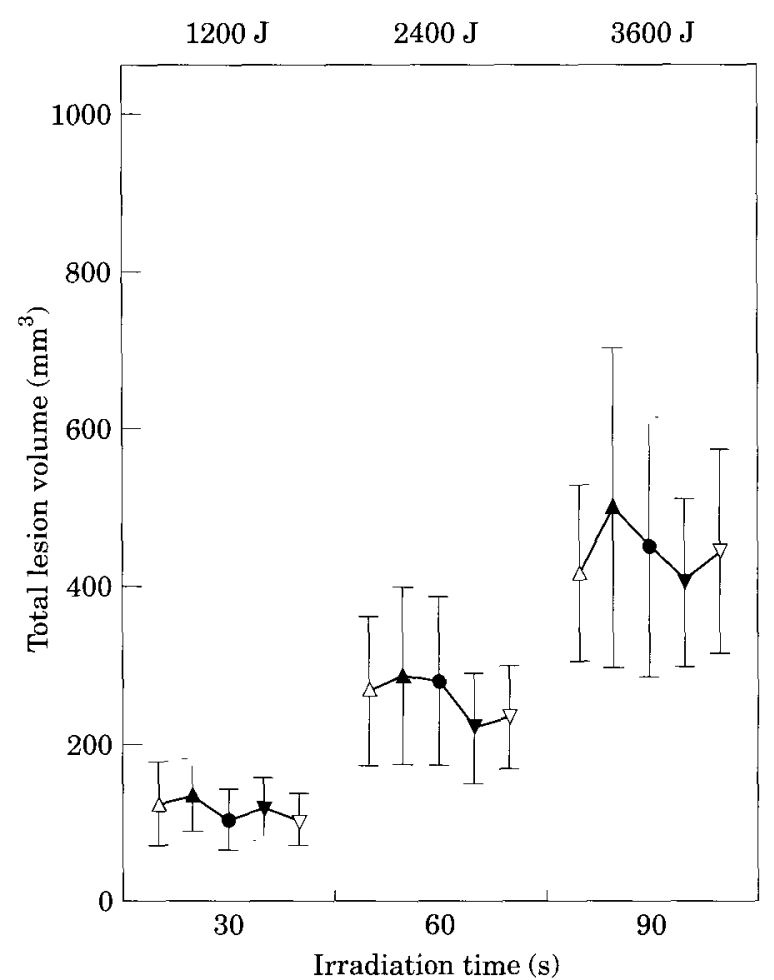

Fig. 3. Total lesion volumes induced in chicken breast as a function of wavelength combinations and irradiation time. No statistically significant difference is observed between the different wavelength combinations $(p=0.33)$. Only an increase of the irradiation time leads to a significant increase of the lesion volume. $\triangle$, Nd-YAG 40 W/KTP O W; $\boldsymbol{\Delta}$, Nd-YAG $30 \mathrm{~W} / \mathrm{KTP} 10 \mathrm{~W} ; \bullet$, Nd-YAG $20 \mathrm{~W} / \mathrm{KTP} 20 \mathrm{~W} ; \mathbf{\nabla}$, Nd-YAG $10 \mathrm{~W} / \mathrm{KTP} 30 \mathrm{~W} ; \nabla$, Nd-YAG O W/KTP $40 \mathrm{~W}$.

$(p<0.0001)$ [Fig. 5(b)]. Third, in contrary to the diameter and the volume, the ablation depth of the crater is significantly increased $(p=0.0002)$ [Fig. 5(c)]. Thus, $532 \mathrm{~nm}$ irradiation after previous irradiation at $1064 \mathrm{~nm}$ induces a forward enhancement of the ablation process.

\section{DISCUSSION}

The concept of dual wavelength irradiation was initially proposed to combine deep coagulation induced by the penetrating $1064 \mathrm{~nm}$ irradiation with immediate tissue removal by the well absorbed $532 \mathrm{~nm}$ irradiation (8). However, due to the tissue alteration induced by the initial $1064 \mathrm{~nm}$ irradiation, the subsequent interaction of the $532 \mathrm{~nm}$ irradiation with the tissue is changed, exhibiting specific tissue effects.

The authors' findings confirm that proper combination of the two wavelengths results in increased lesion depths when compared to isofluent single wavelength irradiation (Fig. 1). 


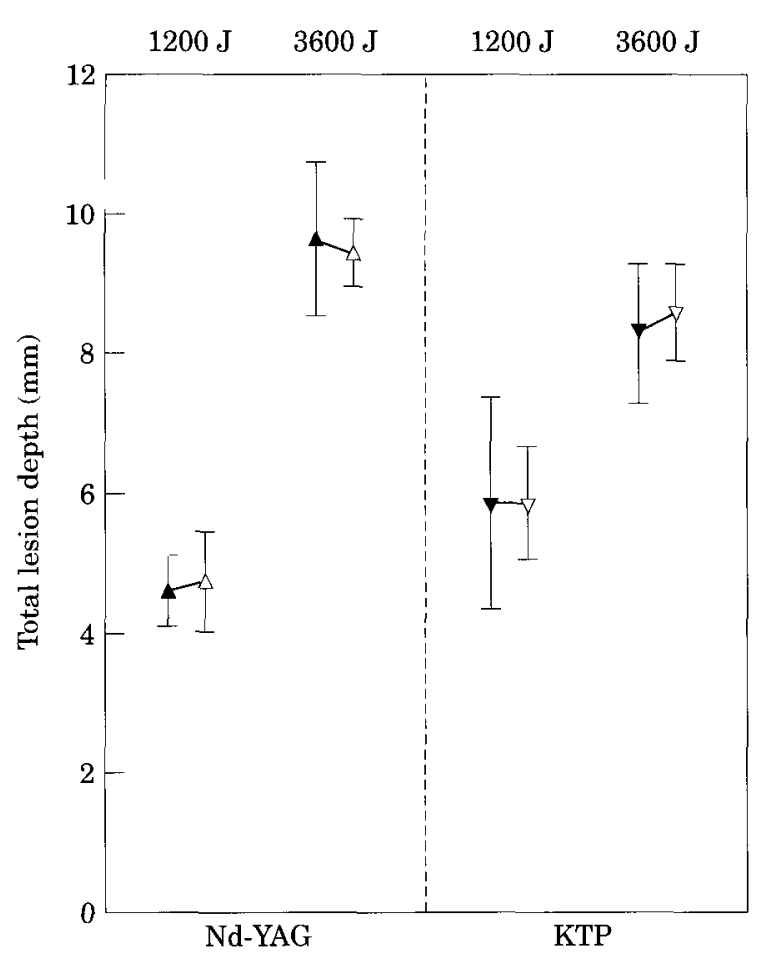

Fig. 4. Total lesion depths induced in chicken breast by the $\mathrm{Nd}$-YAG (1064 nm) and the KTP $(532 \mathrm{~nm})$ lasers as a function of the irradiance. No significant effect of the irradiance on the total lesion depth is found for both laser doses $(p=0.87)$. $\triangle$, Nd-YAG $20 \mathrm{~W} ; \boldsymbol{\Delta}$, Nd-YAG $40 \mathrm{~W} ; \nabla, \mathrm{KTP} 20 \mathrm{~W} ; \boldsymbol{\nabla}, \mathrm{KTP}$ $40 \mathrm{~W}$.

At the investigated irradiation conditions, the maximum synergy occurs at equal irradiance (or laser power). Simultaneously, a decrease of the total lesion diameter can be observed. Thus, as the lesion propagates deeper for the $20 \mathrm{~W} / 20 \mathrm{~W}$ combination, this means that the laser action is more directional for the $20 \mathrm{~W} /$ $20 \mathrm{~W}$ combination than for all others.

The underlying cause for the observed changes in the total lesion depth is related to the modified interaction process between the $532 \mathrm{~nm}$ laser beam and the tissue altered by the initial $1064 \mathrm{~nm}$ irradiation. Two main effects can be expected from the initial $1064 \mathrm{~nm}$ irradiation: a change in the optical properties of the tissue or in its thermal properties. Changes in the optical tissue properties modify the laser energy distribution within the tissue. The optical changes observed after irradiation with the Nd-YAG wavelength are visible blanching and reduction of pigmentation. As a result, the $532 \mathrm{~nm}$ irradiation is less absorbed and more scattered. This effect would lead to an increase of the collateral damage and a reduction of the depth of the tissue lesion. The authors' experiments confirm that prior $1064 \mathrm{~nm}$ irradiation reduces the amount of immediate tissue removal by the KTP. Less efficient laser-tissue interaction leads to a significant reduction $(p<0.0001)$ of the ablated volume (Fig. 5).

Thermal denaturation of the tissue leads to a change in the heat diffusion within the irradiated (coagulated) area. Thus, an increase of the tissue temperature within the irradiation zone due to an insulation effect by the surrounding coagulated layers is expected. This effect could even be enhanced in the living tissue by additional insulation due to reduction of the local tissue perfusion. The depths of the coagulation zone and of the crater cavity are therefore increased. Simultaneously, their diameters are reduced by enhanced heat confinement by the surrounding denatured tissue. This is in agreement with the enhanced coagulation depths observed in the authors' experiments.

Irradiance, ie the rate of laser energy deposition or rate of heating, did not affect significantly the coagulation depth for the treatment times used in this study. This is shown by separate investigations for both wavelengths at different power densities and different irradiation times (Fig. 4).

In summary, in the studied long-lasting irradiation conditions, initial tissue denaturation with the Nd-YAG output reduces the lateral heat diffusion, thus increasing the tissue temperature at the laser impact zone. This leads to an enhanced rate of tissue denaturation by the $532 \mathrm{~nm}$ wavelength in the forward direction, resulting in a deeper tissue lesion.

These results were obtained under ex vivo conditions on chicken breast samples. Chicken breast ex vivo shows similar optical properties at the $\mathrm{HeNe}$ wavelength $(632 \mathrm{~nm})$ to human prostate tissue (12). It most likely resembles prostate tissue with little glandular content, and preliminary results obtained on a limited number of human prostate tissue specimens ex vivo suggest the same synergy effect. Theoretically, one could expect an alteration of the results in vivo due to persistence of blood flow and the varying stromal/epithelial ratio in the prostate. Prior coagulation by the $1064 \mathrm{~nm}$ wavelength leads to a reduction of local blood perfusion. The possible influence of blood perfusion on tissue distribution of the subsequent $532 \mathrm{~nm}$ wavelength is therefore limited. However, further data obtained from in vivo dual wavelength irradiation on human prostate tissue will be needed to confirm this hypothesis. In vivo studies on the prostate are 

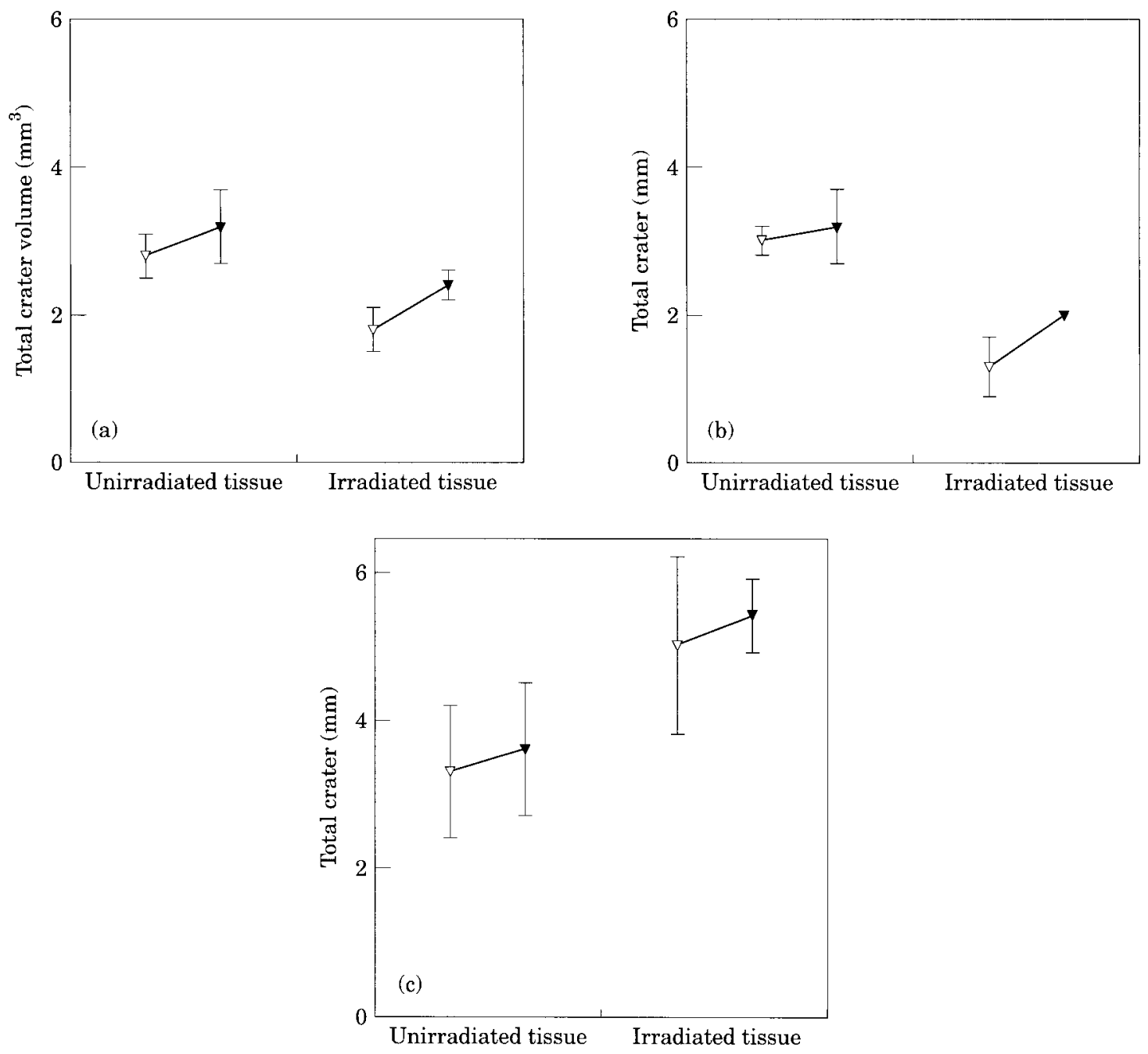

Fig. 5. Effect of prior Nd-YAG (1064 nm) tissue denaturation on the ablation efficacy of the KTP (532 $\mathrm{nm}$ ) in chicken breast on the volume of the ablation crater (a), its diameter (b) and its depth (c). Note that the volume and the diameter are significantly reduced; by contrast, the depth is increased. $\nabla$, KTP $20 \mathrm{~W} ; \boldsymbol{\nabla}, \mathrm{KTP} 30 \mathrm{~W}$.

complicated by the fact that no valid animal model exists. So far, experimental studies have generally been performed with the canine prostate model. However, significant differences in the physical properties as well as anatomical characteristics (ratio of glandular vs stromal tissue) between the canine and human prostate have been reported (3). Such differences may explain the variations in the extent of coagulation necrosis and subsequent elimination of prostate tissue observed in human as compared to the canine prostate data.

\section{Clinical implications}

For improvement of non-contact laser prostatectomy, three aspects have to be considered. First, the induction of deep coagulation is the prerequisite for long-term tissue removal. Thus, the coagulation depth has to be increased in order to yield larger volumes of denatured tissue and ensure better long-term results. Second, a sufficient incision of the urethral prostate is essential in order to increase the immediate benefit of the procedure, allowing early catheter removal, and thereby decreasing postoperative morbidity. Third, dual wavelength irradiation should not complicate laser application or significantly lengthen the treatment time.

The synergy effect found in the present ex vivo study indicates the possibility of increasing the coagulation depth, and thus the coagulation volume, by a dual wavelength tissue ablation concept (Nd-YAG/KTP). Lateral extension of the resorption volume, needed for an increase of the overall coagulation volume of the prostate, can be easily obtained by 
lateral displacement of the fibre. Although the vaporization efficiency of the KTP is reduced after initial Nd-YAG irradiation, the depth of the ablation crater is increased. Thus, a sufficient opening of the urethral channel can be expected allowing a reduction in the postoperative morbidity. Additionally, in the authors' clinical experience (13), dual wavelength irradiation of the prostate does not lengthen the treatment time when compared to the standard TURP procedure or Ho-YAG laser resection.

The potential benefits of the proposed dual wavelength $\mathrm{Nd}-\mathrm{YAG} / \mathrm{KTP}$ laser procedure may thus increase the long-term tissue removal while still enabling sufficient incision of the urethral prostate and preventing the patient from suffering bleeding and fluid resorption. However, the observed synergy effect needs to be confirmed in clinical trials. In these trials, the practical procedure needed to apply the concept demonstrated in vitro will be developed. During these procedures, surgeons should also be aware of possible hazards resulting from the enhanced forward propagation of laser-induced thermal effects. In particular, deeper tissue penetration may increase the risk of perforation, especially when treating the posterior capsule of the prostate.

\section{CONCLUSION}

This study suggests that dual wavelength irradiation with the $\mathrm{Nd}-\mathrm{YAG} / \mathrm{KTP}$ laser exhibits specific ablation properties. At a $20 \mathrm{~W} / 20 \mathrm{~W}$ combination, a synergy effect resulting in an increased coagulation depth has been identified. It follows that dual wavelength irradiation may represent a new approach to yield larger volumes of coagulation necrosis needed for effective laser therapy of benign prostate hyperplasia.

\section{ACKNOWLEDGEMENTS}

This research was supported by the Vaud-Geneva Foundation.

\section{REFERENCES}

1 Watson G. Laser prostatectomy: where are we now, and where should we be going? J Endourology 1995, 9:199-203

2 Watson G. Heat and prostate. Eur Urol 1993, 23:60-3

3 Motamedi M, Torres JH, Orihuela E, Pow-Sand M, Cowan DF, Warren MM. Laser photocoagulation of prostate: influence of dosimetry. Lasers Surg Med 1995, 17:49-58

4 Anson K, Seenivasagam K, Miller R, Watson G. The role of lasers in urology. $\mathrm{Br}$ J Urology 1994, 73:225-30

5 Costello AJ, Bowsher WG, Bolton DM. Laser ablation of the prostate in patients with benign prostatic hypertrophy. Br J Urol 1992, 69:603-8

6 Furuya S, Tsukamoto T, Kumamoto Y, Daikuzono N, Liong ML. Transurethral balloon laser thermotherapy for symptomatic benign prostatic hyperplasia: preliminary clinical results. $J$ Endourology 1995, 9:145-9

7 Muschter R, Hofstetter A, Hessel S, Keiditsch E, Rothenberger KH, Schneede P, Frank F. Hi-tech of the prostate: interstitial Laser coagulation of benign prostatic hypertrophy. Proc SPIE 1992, 1643:25-34

8 Anson KM, Watson GM, Shah TK, Barnes DG. Laser prostatectomy: our experience of a technique in evolution. J Endourology 1993, 7:333 6

9 Kabalin JN. Laser prostatectomy performed with a right angle firing $\mathrm{Nd}$ :YAG laser fiber at $40 \mathrm{Watts}$ power setting. $J$ Urol 1993, 150:95-9

10 Kabalin JN, Gill HS, Bite G, Wolfe V. Comparative study of laser versus electrocauery prostatic resection. eighteen month followup with complex urodynamic assessment. J Urol 1995, 153:94-8

11 Narayan P, Fournier G, Indudhara R. Transurethral evaporation of prostate with Nd:YAG laser using a contact free beam technique: results in 61 patients with benign prostate hyperplasia. Urology 1994, 43:833-7

12 Pantelides ML, Whitehurst C, Moore JV, King TA, Blacklock NJ. Photodynamic therapy for localised prostatic cancer: Light penetration in the human prostate gland. J Urol 1990, 143:398 401

13 Oswald M, Schmidlin F, Jichlinski P, Graber P, Leisinger HJ. Combination of thermocoagulation and vaporization using a Nd:YAG/KTP laser versus TURP in BPH treatment. (abstract) J Urol 1997, 157:42

Key words: Coagulation; Laser-tissue interaction; Prostate; Vaporization 